\title{
Effect of Constitutive miR164 Expression on Plant Morphology and Fruit Development in Arabidopsis and Tomato
}

\author{
Flor de Fátima Rosas Cárdenas ${ }^{1, *}{ }^{\dagger}$, Yolanda Ruiz Suárez ${ }^{2,+}$, Rosa María Cano Rangel ${ }^{3}$, \\ Valentín Luna Garcia ${ }^{2}$, Karla Lorena González Aguilera ${ }^{2}$, Nayelli Marsch Martínez ${ }^{4}$ and \\ Stefan de Folter ${ }^{2, *}$
}

1 Centro de Investigación en Biotecnología Aplicada del Instituto Politécnico Nacional (CIBA-IPN), Ex-Hacienda San Juan Molino, Carretera Estatal Tecuexcomac-Tepetitla Km 1.5, Tlaxcala, CP 90700 Tepetitla, Mexico

2 Unidad de Genómica Avanzada (LANGEBIO), Centro de Investigación y de Estudios Avanzados del Instituto Politécnico Nacional (CINVESTAV-IPN), Km. 9.6 Libramiento Norte, Carretera Irapuato-León, Irapuato, CP 36821 Guanajuato, Mexico; ing_yruizs@hotmail.com (Y.R.S.); valentin.luna@cinvestav.mx (V.L.G.); karla.gonzalez@cinvestav.mx (K.L.G.A.)

3 Laboratorio de Transformación, Departamento de Ingeniería Genética, Unidad Irapuato, CINVESTAV-IPN, Km. 9.6 Libramiento Norte, Carretera Irapuato-León, Irapuato, CP 36821 Guanajuato, Mexico; rosarangel_70@hotmail.com

4 Departamento de Biotecnología y Bioquímica, Unidad Irapuato, CINVESTAV-IPN, Km. 9.6 Libramiento Norte, Carretera Irapuato-León, Irapuato, CP 36821 Guanajuato, Mexico; nayelli.marsch@cinvestav.mx

* Correspondence: frosasc@ipn.mx (F.d.F.R.C.); stefan.defolter@cinvestav.mx (S.d.F.); Tel.: +52-55-5729-6000 (ext. 87814) (F.d.F.R.C.); +52-462-1663-011 (S.d.F.)

+ These authors contributed to this work equally.

Academic Editors: Esther van der Knaap and Cecilia E. McGregor Received: 13 April 2017; Accepted: 11 July 2017; Published: 15 July 2017

\begin{abstract}
Several miRNAs are conserved in different plant families, but their abundance and target genes vary between species, organs, and stages of development. Target genes of miRNAs are mostly transcription factors, involved in the control of many plant developmental processes, including fruit development. MiR164 is a conserved miRNA, highly expressed in fruits, and is validated to target a subset of genes of the NAC-domain transcription factor gene family. The objective of this work was to analyze the phenotypic effects of the constitutive expression of miR164 during the life cycle of Arabidopsis and tomato. MiR164 overexpression (164-OE) lines for Arabidopsis and tomato were generated and analyzed during plant development. The constitutive miR164 expression showed that miR164 affected the morphology of Arabidopsis and tomato, and it affected the transition from the vegetative to the reproductive phase in Arabidopsis. Moreover, the miR164 overexpression affected the time required for each developmental stage of tomato fruit. These results suggest that miR164 plays general and specific roles during development in Arabidopsis and tomato, including fruit development, which could be exploited for the improvement of traits of agronomic interest in important species.
\end{abstract}

Keywords: miRNA; miR164; overexpression miRNA; fruit development; tomato; Arabidopsis

\section{Introduction}

MicroRNAs (miRNAs) are short RNAs ( 21 nt) present in eukaryotic organisms. Some miRNAs are evolutionarily conserved from basal plants to higher plants, although their abundance is variable [1-9]. High-throughput sequencing revealed the miRNA diversity of various plant species, including fruit 
producing species such as tomato (Solanum lycopersicum), grape (Vitis vinifera), orange (Citrus sinensis), and papaya (Carica papaya), among others [5]. Likewise, it has been found that the expression level of these molecules varies between species, varieties, organs, etc. (e.g., $[4,5,8]$ ). miRNAs regulate gene expression in a sequence-specific manner by targeting mRNAs for cleavage or translational repression [10-12]. It has also been observed that the number of loci encoding a miRNA and targets of a miRNA vary between species [3]. Furthermore, based on miRNA overexpression and mutant studies, it has been demonstrated that miRNAs are required for many developmental processes in plants [13-21].

In this study we focused on miR164, which is a highly conserved miRNA in the plant kingdom [5]. The gene family of miR164 contains three members in Arabidopsis, MIR164A, MIR164B, and MIR164C [22,23], and two members in tomato, MIR164A and MIR164B [24]. It has been shown that miR164 negatively regulates a subset of members of the NAC transcription factor family [13,25-27]. The first attributed function to miR164 was the regulation of the Arabidopsis CUC1 (CUP-SHAPED COTYLEDON1) and CUC2 genes, which are involved in tissue differentiation [25,28-37]. Moreover, the regulation of $C U C 1$ and CUC2 genes by miR164 is required for correct floral organ boundary formation during flower development $[25,26,28]$. Currently, other genes such as ORESARA1 (ORE1), NAC1, At5g07680, and At5g61430 have been validated as target genes of miR164 in Arabidopsis $[13,38,39]$. In tomato, GOBLET (GOB), NAC1, NAM2, and NAM3 are target genes of miR164 [24,34,40]. The overexpression of miR164 in Arabidopsis and tomato affects leaf and floral organ development $[24,25,34]$, and the loss of function of the MIR164C gene results in the growth of extra petals in Arabidopsis [26]. Furthermore, it has been observed that miR164 is also involved in senescence of leaves in Arabidopsis [13,41]. In addition, interestingly, miR164 is one of the most abundant miRNAs in some fruits such as orange [42], grape [43,44], tomato [45], and prickly pear fruit (tuna) [46]. In orange, it was observed that miR164 has remarkably higher expression in fruits in comparison with other organs [42]. Moreover, miR164 accumulates to high levels during fruit ripening $[42,45,46]$.

Therefore, in this work we studied the effect of miR164 overexpression in the reproductive phase and the process of fruit development, besides general plant development, in transgenic 35S::miR164 Arabidopsis and tomato plants. Based on our results, and based on others, we suggest that miR164 plays general and specific roles during plant development in Arabidopsis and tomato, including fruit development, which could be exploited for the improvement of traits of agronomic interest in different species.

\section{Results}

\subsection{Characterization of miR164 Overexpression in Arabidopsis}

Arabidopsis plants were transformed with a 35S::miR164 construct, and BASTA resistant T2 lines (164-OE) were used for phenotypic analyses. In general, a decrease in plant size was observed (Figure 1a). We analyzed six lines in detail. From them, five lines (line 1, 2, 3, 4, and 6) presented a clear decrease in rosette leaf serration compared with wild type (WT) plants (Figure 1b), as expected. Furthermore, to verify if the 35S::miR164 construct was functional, we analyzed the expression of the miR164 target gene CUC1 by RT-PCR and observed that in all transgenic lines CUC1 transcripts were not detected anymore (Figure 1c), demonstrating that the 35S::miR164 construct was functional. In one line, 164-OE line 5, no clear decrease in leaf serration was observed, although CUC1 downregulation was also detected in this line. Also, a clear increase of pre-miR164a in 164-OE lines of Arabidopsis was observed (Figure S1a).

Moreover, the 164-OE lines presented differences in plant architecture and fusion events (Figure 2a-d). Most of the 164-OE plants presented significantly more branches in the main stem (Figure 2a,b). On the other hand, less secondary stems were observed in young plants (Figure 2c), but in mature plants the number of secondary stems was similar compared to wild type plants (Figure 2c), suggesting that the constitutive miR164 expression may delay the production of secondary stems in 
Arabidopsis plants (Figure 2c). Moreover, a delay in the transition of the vegetative to the reproductive stage was observed, which was significant in four out of six lines analyzed (Figure 2d). Another observed phenotype was the fusion of organs, which has been reported for the overexpression of miR164 and for the downregulation of its target genes [24,32,37]. We observed several degrees of organ fusion such as fusions of stems and branches, and of leaves (Figure 3a). Also an increased number of cauline leaves was observed. With respect to the degree of severity of the phenotypes, plants of each 164-OE line were grouped into the following classes: normal, light, and severe phenotype (Figure 3a,b).

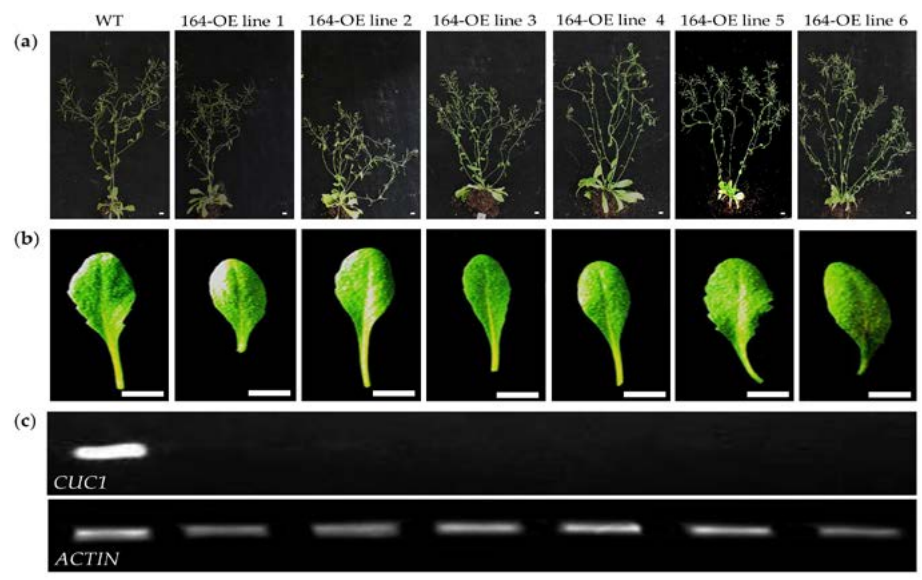

Figure 1. Phenotypic and molecular analyses of 164-OE Arabidopsis lines. (a) Adult plants of different 164-OE lines; (b) Leaves of different 164-OE lines; (c) Expression analysis of the CUC1 gene in the different 164-OE lines. RT-PCR was performed on cDNA of rosette leaves of the different lines. Scale bars $=1 \mathrm{~cm}$.

(a)
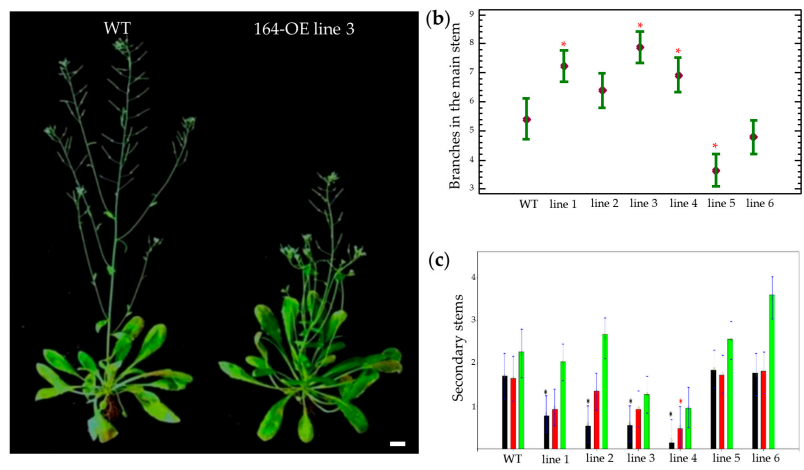

(d)

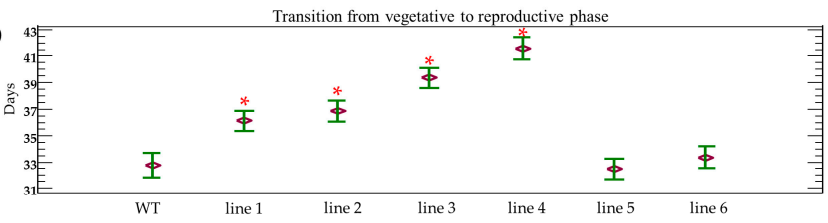

Figure 2. Phenotypic effects observed in the 164-OE Arabidopsis lines. (a) Plants with more severe phenotypes of 164-OE lines. Scale bar $=1 \mathrm{~cm}$; (b) Quantification of branches in the main stem (WT $n=15$, line $1 n=26$, line $2 n=21$, line $3 n=26$, line $4 n=21$, line $5 n=25$, line $6 n=22$ ); (c) Quantification of secondary stems at 7 (black bars), 9 (red bars), and 11 (green bars) weeks post-germination (WT $n=17$, line $1 n=26$, line $2 n=26$, line $3 n=27$, line $4 n=21$, line $5 n=25$, line $6 n=22$ ); (d) Days required for the transition from the vegetative to the reproductive phase (WT $n=17$, line $1 n=26$, line $2 n=26$, line $3 n=27$, line $4 n=21$, line $5 n=25$, line $6 n=22$ ). $n$, indicates the number of plants analyzed. For all cases, the means and Least Significant Difference (LSD) intervals at a confidence level of $95 \%$ were plotted. * indicates that there is a statistically significant difference. 

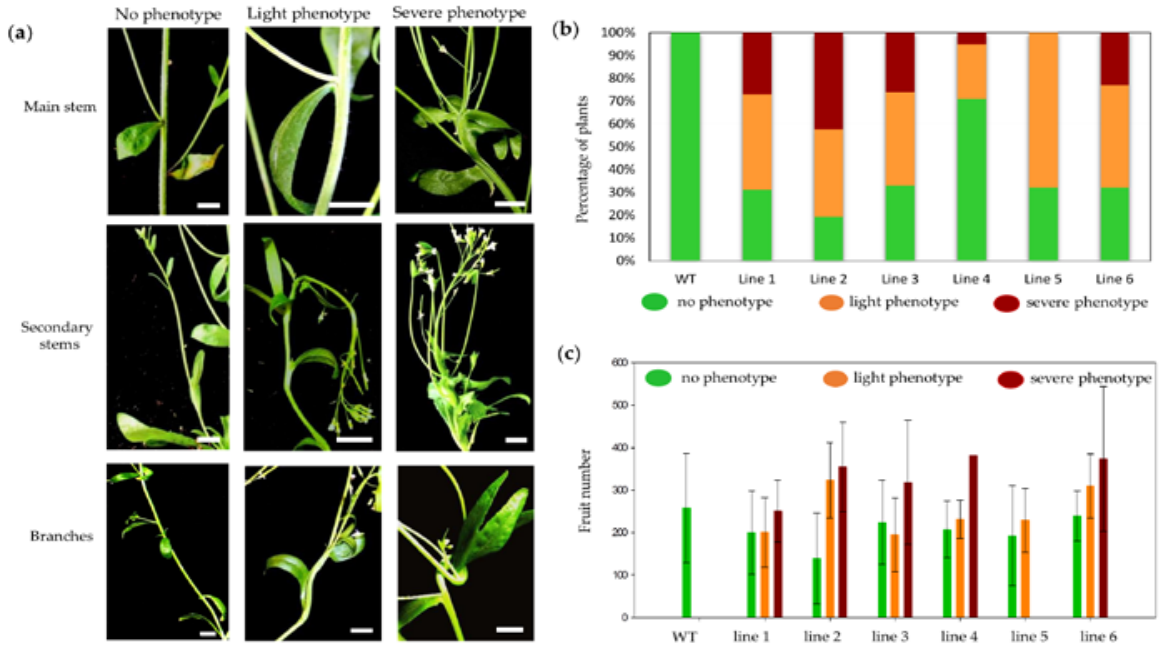

Figure 3. Classification of phenotypes observed in 164-OE Arabidopsis lines. (a) Phenotype classification and (b) Percentage of plants observed for each phenotype; (c) Quantification of fruits in 164-OE Arabidopsis lines (WT $n=15$, line $1 n=26$, line $2 n=21$, line $3 n=26$, line $4 n=21$, line $5 n=25$, line $6 n=22$ ). $n$ indicates the number of plants analyzed. For all cases, the means and LSD intervals at a confidence level of $95 \%$ were plotted. Scale bars $=1 \mathrm{~cm}$.

Finally, regarding the number of fruits, although not statistically significant, a trend was observed in which plants with a higher degree of organ fusion defects presented an increased number of fruits compared to wild type plants (Figure 3c), which could have to do with altered hormone homeostasis, and this would be interesting to study in the future.

\subsection{Characterization of miR164 Overexpression in Tomato}

Tomato Micro-Tom (MT) Rg1 plants were transformed with a 35S::miR164 construct, the same construct as was used for Arabidopsis transformation and shown to be functional (note: the mature miR164 sequence is the same in Arabidopsis and in tomato). The phenotypic characterization in tomato was performed in the T2 generation of BASTA resistant independent transgenic lines. In general, the 164-OE tomato plants from the independent lines were smaller in size compared to wild type plants (Figure 4a and Figure S2). Furthermore, the leaves were smaller and some of them had a decrease in serrations in their leaflets (Figure 4a,b), phenotypes that have previously been reported [29,33]. The presence of the BAR gene located on the T-DNA was detected by PCR in genomic DNA of plants of the analyzed lines (Figure 4c), indicating that they are transgenic. Although, in contrast to Arabidopsis, we could not conclusively detect overexpression of pre-miR164a (Figure S1b). Still, it is likely that miR164 is more abundant compared to wild type plants because the expected leaf alterations were observed; however, future experiments detecting the abundance of the mature miRNA would be necessary to conclude.

Furthermore, we also observed other, not yet described phenotypes. In plants of two lines, 164-OE line 2 and 164-OE line 5, we observed a delay in fruit production (Figure 5a,b). The number of days needed to observe the first fruit of $3 \mathrm{~mm}$ in diameter was on average 48 days after germination in 164-OE line 2 and 55 days in 164-OE line 5 compared to 44 days in wild type plants (Figure 5b). Furthermore, we analyzed the number of locules, the number of fruits, fruit size, and seed number (Figure $5 \mathrm{c}-\mathrm{g}$ ). The number of locules was significantly increased in 164-OE lines 1, 2, and 3, and decreased in 164-OE line 5 (Figure $5 c, d$ ). A significant increase in the number of fruits was observed in 164-OE line 5 (Figure 5e). The size of the fruits by measuring the diameter was significantly altered in various lines, increased in 164-OE lines 3 and 6 (in 164-OE line 4 the increase is not significant), and decreased in 164-OE line 5 
(Figure 5f). Furthermore, seed number was significantly increased in 164-OE line 6, which also had larger fruits. In 164-OE line 5, a decreased number of seeds per fruit was observed (Figure 5g).

(a)

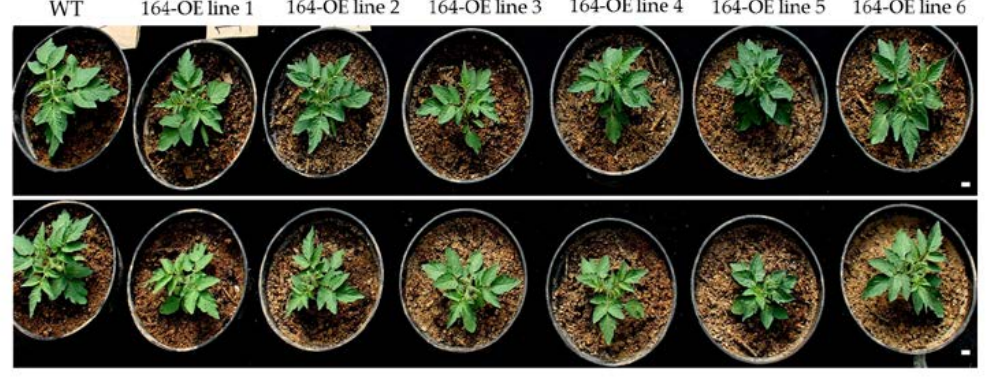

$(\mathrm{b})$

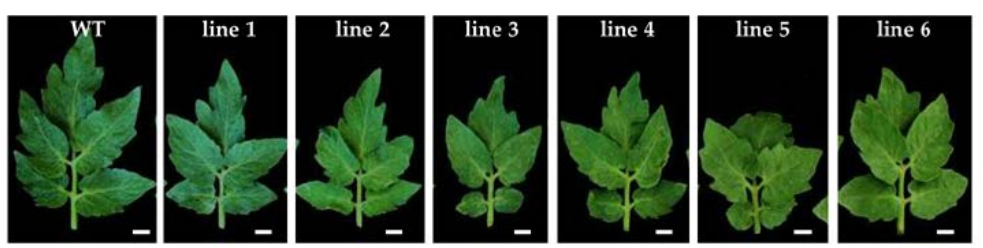

(c)

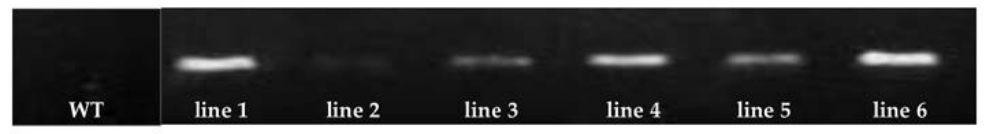

Figure 4. Phenotypic and molecular analyses of 164-OE tomato lines. (a) Plants and (b) leaves of different 164-OE tomato lines. Two plants of each line are shown, the leaf presented is the third leaf; (c) Detection of the BAR gene on the T-DNA in genomic DNA from the transgenic 164-OE tomato lines by PCR. Scale bars $=1 \mathrm{~cm}$.

(a)

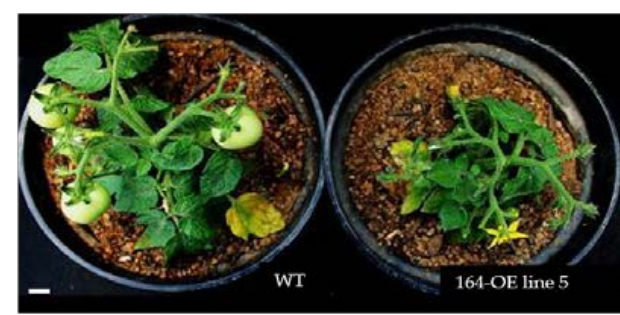

(c)

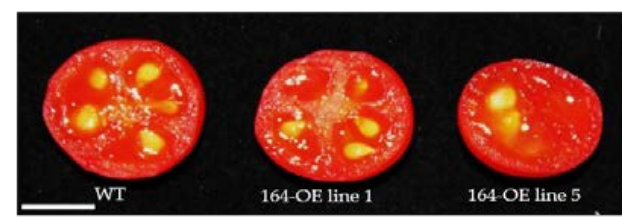

(e)

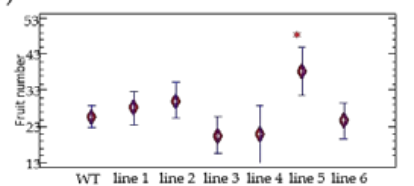

(f)

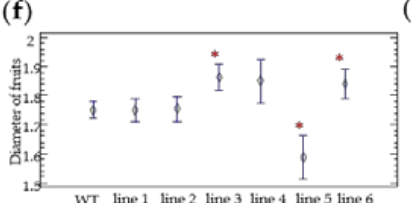

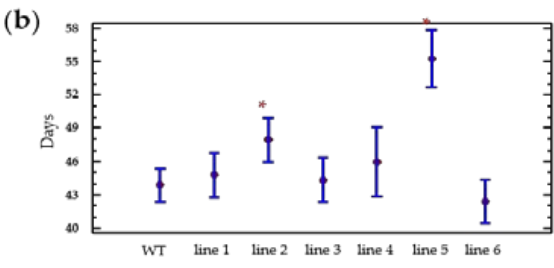

(d)

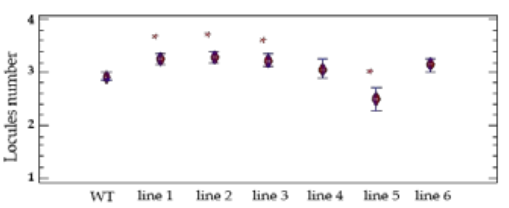

(g)

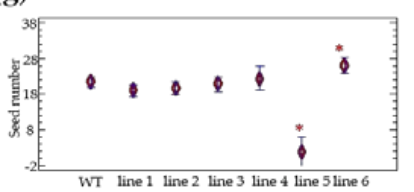

Figure 5. Effect of miR164 overexpression on fruits of tomato. (a) Comparison of wild type (WT) and 164-OE line 5 plants of 50 days of age; (b) Days that the different lines required to develop the first fruit, WT $n=10$, line $1 n=5$, line $2 n=5$, line $3 n=5$, line $4 n=3$, line $5 n=3$, line $6 n=6$; (c) Effect in the locule number; (d) Number of locules per fruit plotted for each line, (WT $n=215$, line $1 n=128$, line $2 n=108$, line $3 n=94$, line $4 n=33$, line $5 n=26$, line $6 n=73$ ); (e) Fruit number; (f) Diameter of fruits; and (g) Seed number in fruits of the different 164-OE lines. $n$ indicates the number of plants or fruits analyzed. For all cases, the means and LSD intervals at a confidence level of $95 \%$ were plotted. * indicates that there is a statistically significant difference. Scale bars $=1 \mathrm{~cm}$. 
We also analyzed the amount of days needed for each stage of fruit development (Figure 6). Differences were observed at certain developmental stages in the different lines, but according to ANOVA analysis the total duration of tomato fruit development was not significantly affected (Figure 6a,b). However, a significant change in the time required for some specific stages of fruit development was detected (Figure 6c). Four out of six lines (164-OE line 2, 3, 5, and 6) presented a significant decrease in the time for completion of developmental stage 2 and stage 3 , which corresponds to the stages characterized by cell division and to cell expansion, respectively (Figure 6c). At the ripening stage (stage 4), the 164-OE line 4 and 164-OE line 5 fruits required more time to mature than fruits of wild type plants. Finally, at stage five, fruits of plants of 164-OE line 3 and 164-OE line 5 fruits presented a faster senescence than fruits of wild type plants, but fruits from 164-OE line 6 appeared to have the opposite effect (these remained firm for a longer time than fruits of wild type plants). These results suggest that although the overall effect is not significant, miR164 affects different stages of tomato fruit development.

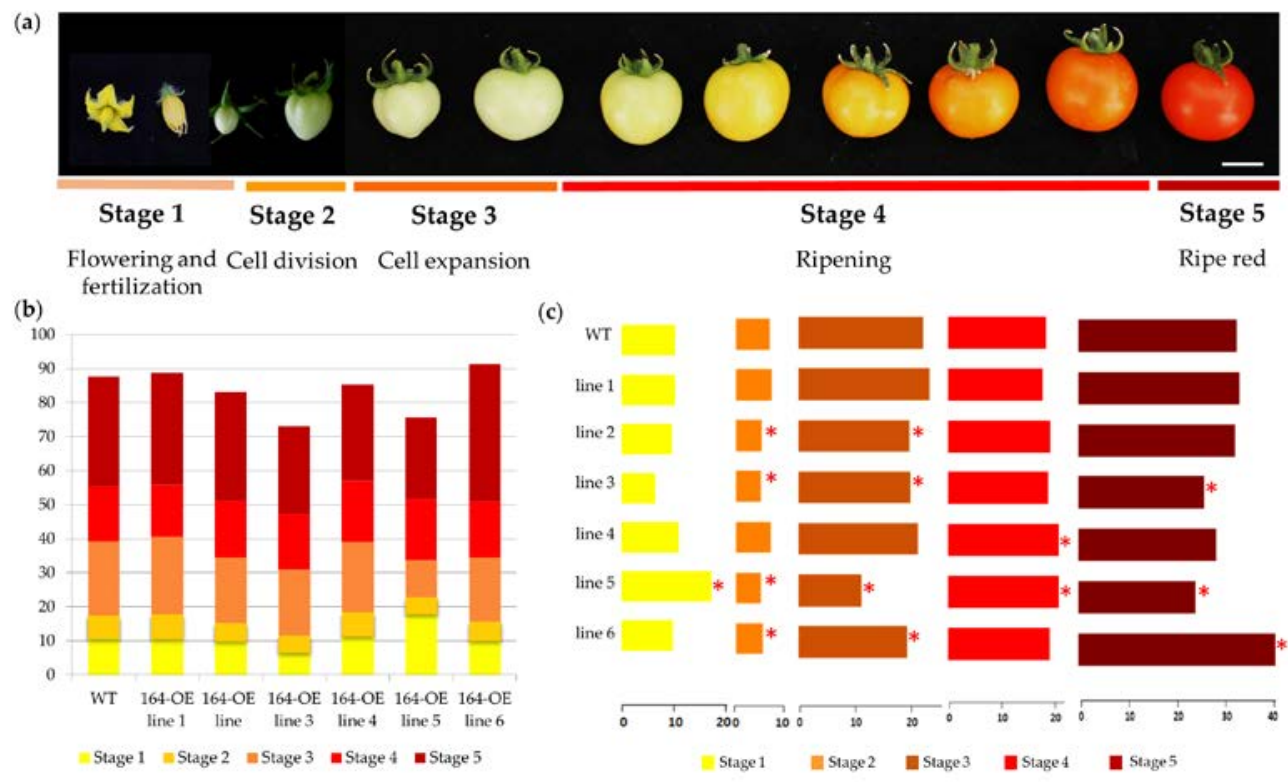

Figure 6. Duration of developmental fruit stages in 164-OE tomato lines. (a) Overview of tomato MT-Rg1 fruit development; (b) Total duration of tomato MT-Rg1 fruit development; (c) Time required for some specific stages of tomato fruit development. The graph shows the average number of days that the fruits required in each stage during their development. Stage 1 (WT $n=32$, line $1 n=14$, line $2 n=27$, line $3 n=10$, line $4 n=3$, line $5 n=19$, line $6 n=50)$. Stage 2 (WT $n=208$, line $1 n=106$, line $2 n=76$, line $3 n=66$, line $4 n=26$, line $5 n=43$, line $6 n=71)$. Stage $3(\mathrm{WT} n=216$, line $1 n=107$, line $2 n=85$, line $3 n=74$, line $4 n=28$, line $5 n=44$, line $6 n=65)$. Stage $4(\mathrm{WT} n=207$, line $1 n=120$, line $2 n=105$, line $3 n=83$, line $4 n=27$, line $5 n=40$, line $6 n=61)$. Stage 5 (WT $n=122$, line $1 n=65$, line $2 n=61$, line $3 n=71$, line $4 n=25$, line $5 n=25$, line $6 n=51$ ). $n$ indicates the number of fruits analyzed. For all cases, the means and LSD intervals at $95 \%$ were plotted. * indicates that there is a statistically significant difference. Scale bar $=1 \mathrm{~cm}$.

Finally, we started an expression analysis of some target genes of miR164 in tomato. NAC1, NAM2, NAM 3, and GOB expression was detected by RT-PCR in wild type and 164-OE flowers. In general, the expression of all genes was still detected, but some alterations were observed (Figure 7). Less expression of $N A C 1$ was observed in the 164-OE lines 2 and 3. Less expression of NAM2 was observed in the 164-OE lines 2, 3, 5, and 6. For NAM3, less expression was detected in the 164-OE lines 3,5 , and 6 . The detected expression of $G O B$ was increased in almost all lines, which we cannot explain well, perhaps because expression of $G O B$ changes rapidly during flower development and our wild type flower sample was slightly shifted in time compared with the other samples. On the other hand, 
positive correlations between microRNA and the expression of target genes have been observed before in tomato [45].

(a)
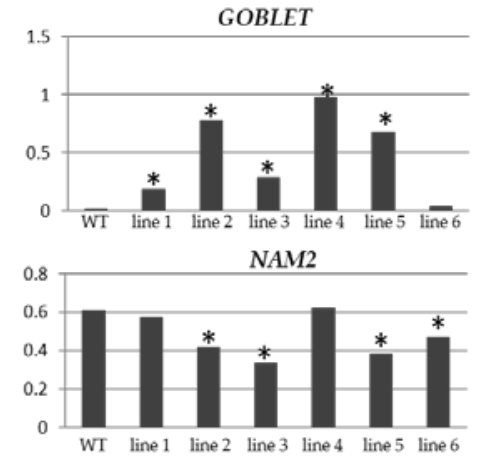

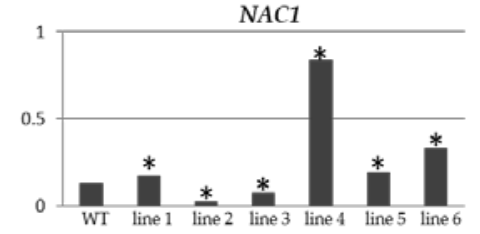

NAM3

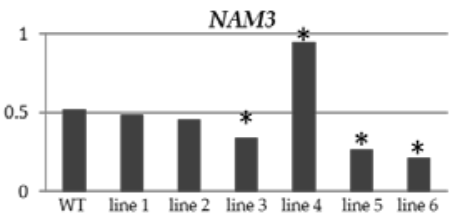

(b)

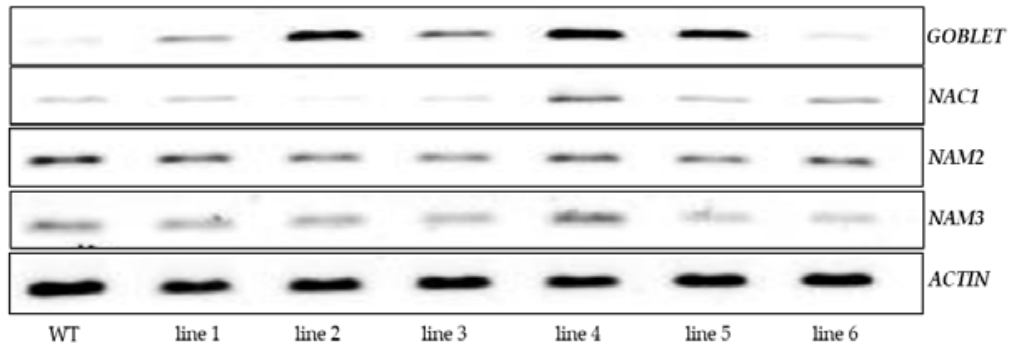

Figure 7. Expression analyses of miR164 target genes in 164-OE tomato plants. (a) Relative expression of miR164 target genes based on RT-PCR data; (b) RT-PCR of miR164 target genes in 164-OE tomato plants. Flower tissue of the different lines with constitutive miR164 expression was used. * indicates that there is a statistically significant difference.

\section{Discussion}

\subsection{Overexpression of miR164 Affects Plant and Organ Shape}

The Arabidopsis and tomato 164-OE lines resulted in various morphological alterations. In general, 164-OE plants were smaller than wild type plants and the leaves of Arabidopsis and tomato 164-OE lines showed a reduction in margin serrations and were smaller. Reduction of leaf margin serration as a result of increased miR164 expression is a phenotype that has been previously reported as linked to a reduction of CUC expression [28,29,31-34]. Furthermore, fusion events were observed in different organs and tissues of Arabidopsis, phenotypes that had also been previously reported to be related to miR164 expression [25,32,34-37]. The activity of the NAM/miR164 module in the Arabidopsis leaf margin has been modeled and found to generate an alternating series of auxin maxima and minima that generates regions of higher and lower marginal growth, respectively, which are associated with serrations and fusions in leaves [47]. In eudicots, orthologous NAM transcription factors are expressed at organ margins and tissue boundaries, and their downregulation by miR164 consequently facilitates organ outgrowth and/or developmental fusion [37]. Furthermore, in tomato, some lines had a reduction in the number of locules, which coincided with a report on tomato fruits of gob-3 and Gob-4d mutants, where it was found that these mutants produced flowers with fused sepals, and fruits with less locules or with extra carpels, respectively [34].

We observed that the phenotype severity varied between lines and within the lines, both in tomato and Arabidopsis (Figures 1-6), which likely has to do with the level of expression of miR164 in different plants. It has been reported that the different expression levels of a miRNA may cause differences in phenotype severity. For example, miR164 overexpression in Cardamine hirsuta resulted in plants with phenotypic alterations with different degrees of severity [34]. Moreover, the regulatory 
network controlling shoot meristem activity is likely to have played an important role in morphological diversification, and it has been demonstrated that miR164 modulates the activity of meristematic tissues [48]. Thus, the difference in plant shape may be associated with the expression level of miR164.

\subsection{Overexpression of miR164 Affects the Transition from the Vegetative to the Reproductive Phase}

Previously it has been reported that some miRNAs (miR156 and miR172) are involved in the transition from the vegetative to the reproductive phase $[49,50]$. Although various effects of miR164 have been reported previously, an effect on the time of the vegetative phase change has not been reported to our knowledge. Interestingly, it has been demonstrated that age-dependent cell death is delayed in ore1 mutants, and ORE1 is a target gene of miR164 [13]. Here, we found that in the case of Arabidopsis, there exists a delay in the transition from the vegetative to the reproductive phase in the different lines (Figure 2d). In the case of tomato, this effect was not clear; however, we observed that some lines had a delay in the generation of their first fruit (Figure 5a,b). In summary, the data suggest that miR164 also affects phase changes in plants.

\subsection{Overexpression of miR164 Affects the Time Required for Each Stage of Tomato Fruit Development}

MiR164 functions in the regulation of age-dependent cell death in leaves through changes in its expression level over the life span of the leaves [13]. The NAM/miR164 module is involved in leaf, carpel, and ovule development in model angiosperms [29,31,37,51,52]. In a previous study in the fruit of the prickly pear cactus, we found that miR164 is present in all developmental stages, and the temporal expression suggests that miR164 has different functions during fruit development of prickly pear fruit [46]. The results obtained in this study (Figure 6) showed that the time required for stages of fruit development was affected to different extents in the 164-OE lines, suggesting that miR164 can affect tomato fruit development.

We analyzed the expression of some miR164 target genes. In the Arabidopsis 164-OE lines, we found a clear down-regulation of CUC1 expression in all lines. In tomato, we found down-regulation of various target genes in different 164-OE lines, but we observed variation among the lines. We detected overexpression of the pre-miR164a in Arabidopsis, but in tomato it was not conclusive. Perhaps in tomato the miRNA processing could be different than in Arabidopsis, and at the moment we can only speculate that the variation of phenotypes may be caused by differences in abundance of mature miR164. Nevertheless, we observed an increase in GOB expression, i.e., a positive correlation between miRNA and the target gene, and not the normal negative correlation. Interestingly, in wild type tomato plants $G O B$ and miR164 are expressed in complementary domains, in contrast to Arabidopsis [34]. Positive correlations between microRNA and expression of target genes has been observed before in tomato, leading to the suggestion that mutual exclusion could be as widespread as temporal regulation [45]. Furthermore, the correlation may also change during development [45]. In summary, we cannot currently pinpoint which target genes are responsible for the observed phenotypes; however, the results suggest that miR164 causes the observed phenotypes.

\section{Materials and Methods}

\subsection{Plant Growth and Plant Material}

Arabidopsis thaliana ecotype Columbia-0 (Col-0) plants were grown under greenhouse conditions with natural light (in autumn; short-days). This was done in a mixture of sunshine, perlite, and vermiculite in relation 3:1:1, respectively. Tomato (Solanum lycopersicum) Micro-Tom (MT) Rg1 genotype plants [53] were grown under greenhouse conditions with natural light (in summer; long days) in a mixture of leaf soil, soil, sand, and perlite in a ratio of 3:1:1:1, respectively. The tissues were collected, frozen in liquid nitrogen, and stored at $-80{ }^{\circ} \mathrm{C}$ until further use. 


\subsection{Vector Construction}

A fragment of 291 nucleotides containing the pre-miR164a hairpin structure was amplified by PCR from Arabidopsis thaliana cDNA using oligonucleotides miR164-Fw (5'-TGC GTG TGA GCT AGT CTT CC-3') and miR164-Rv ( $5^{\prime}$-CAA CGA AGA GCT AGT CAA GAA CAA-3'). The fragment was subcloned in the vector $\mathrm{pENTR/D-TOPO} \mathrm{(Invitrogen,} \mathrm{Carlsbad,} \mathrm{CA,} \mathrm{USA)} \mathrm{and} \mathrm{sequence} \mathrm{verified} \mathrm{by}$ sequencing, followed by recombining with the plant binary vector pB7WG2D (containing the 35S promoter, to generate the overexpression of miR164).

\subsection{Arabidopsis Transformation}

For transformation and selection of Arabidopsis transgenic lines, the plants were transformed using the floral-dip method [54] and T1 transformants were identified through BASTA selection on soil (solution of $300 \mu \mathrm{M}$ of BASTA) and, at maturity, seeds were collected. Arabidopsis T2 seeds were germinated and the transgenic lines were selected again with the BASTA herbicide. Thirty T2 plants of each 164-OE line were used for subsequent analyses. Plants could still be segregating for the T-DNA.

\subsection{Tomato Transformation}

Tomato seeds MT- $R g 1$ were sterilized with $20 \%$ commercial bleach $(v / v)$. Seeds were germinated on MS medium ( $4.45 \mathrm{~g} / \mathrm{L}$ of MS salts, $6 \mathrm{~g} / \mathrm{L}$ of agar, $15 \mathrm{~g} / \mathrm{L}$ of saccharose) for ten days. Then, cotyledon explants were cut into three parts and placed in a liquid MS medium $(4.45 \mathrm{~g} / \mathrm{L}$ of MS salts, $15 \mathrm{~g} / \mathrm{L}$ of saccharose) (diluted 1:10). Agrobacterium tumefaciens containing the 35S:::miR164 construct was grown in LB medium with the appropriate antibiotics (spectinomycin and rifampicin) to an O.D.600 of 0.2-0.3, and subsequently the culture was diluted 1:10 with MS medium containing $100 \mu \mathrm{M}$ acetosyringone and added to the explants for $20 \mathrm{~min}$ at room temperature. Subsequently, the bacteria were removed and the explants were transferred to a co-culture medium (solid MS medium with 3 MM paper on the agar surface) to remove the excess bacteria. The explants were transferred to plates with solid MS medium and covered with aluminum foil and incubated for $24-48 \mathrm{~h}$ at $25^{\circ} \mathrm{C}$. Next, the explants were transferred to shoot induction medium $(0.5 \times$ MS and with complete vitamins, appropriate agent of selection (BASTA), $0.025 \mathrm{~g} / \mathrm{L}$ of meropenem (or claforan/cefotaxime), and $2 \mathrm{mg} / \mathrm{L}$ of zeatin), and incubated for four to six weeks (during this period various transfers were done to fresh shoot induction medium to prevent/stop bacterial growth) at $25^{\circ} \mathrm{C}$ with $16 \mathrm{~h}$ photoperiod light and $8 \mathrm{~h}$ dark. When shoots were observed, they were transferred to elongation medium (shoot induction medium with $0.3 \mathrm{mg} / \mathrm{L}$ of GA3). After two to three weeks when shoots had long stems, they were cut and transferred to rooting medium (solid MS medium, $0.04 \mu \mathrm{M}$ of NAA) with selection agent against bacteria (meropenem). After that roots appeared (two or three weeks later), plantlets were carefully transferred to soil. For the acclimation of the plantlets, pots were covered with glass or plastic bags for three days, and then they were uncovered for 2 or 3 h every day. Subsequently, shoots were semi-covered for two days, and, finally, shoots were totally uncovered. Tomato fruits were collected from independent T1 plants that were resistant to the BASTA herbicide. Seeds from the T1 fruits were selected with the BASTA herbicide, generating T2 plants for the different lines, which were used for further analyses. Plants could still be segregating for the T-DNA.

\subsection{DNA Extraction and PCR}

For genomic DNA extraction, the samples (around $20 \mathrm{mg}$ of tomato leaf) were ground to a fine powder in a mortar with liquid nitrogen. To the powder, $250 \mu \mathrm{L}$ of Shorty Buffer $(2 \mathrm{M}$ Tris $/ \mathrm{HCl}$ $\mathrm{pH}$ 9.0, $4 \mathrm{M} \mathrm{LiCl}, 25 \mathrm{mM}$ EDTA, 1\% SDS) was added and the samples were centrifuged for $10 \mathrm{~min}$ at $15,000 \mathrm{rpm}$. Subsequently, $175 \mu \mathrm{L}$ of supernatant was transferred to a new tube, and $175 \mu \mathrm{L}$ of isopropanol was added and mixed by inversion, followed by incubation at room temperature by $5 \mathrm{~min}$, followed by centrifugation for $15 \mathrm{~min}$ at $15,000 \mathrm{rpm}$. The supernatant was discarded and the pellet was dried, and finally the pellet was resuspended in $100 \mu \mathrm{L}$ of TE pH 8.0. For PCR analysis, the following 
oligonucleotides were used to amplify the BAR gene: BAR-Fw 5'-TCT GCA CCA TCG TCA ACC ACT ACA- $3^{\prime}$ and BAR-Rv $5^{\prime}$-GCA GCC CGA TGA CAG CGA CCAC- $3^{\prime}$.

\subsection{RNA Extraction and RT-PCR}

RNA extraction was performed using the Trizol method (Invitrogen), according to the manual. Briefly, $1 \mathrm{~mL}$ of Trizol solution was added to $100 \mathrm{mg}$ of tissue, the samples were vortexed for $30 \mathrm{~s}$ and incubated at $30{ }^{\circ} \mathrm{C}$ (10 min for Arabidopsis, and $5 \mathrm{~min}$ at room temperature for tomato). Next, $200 \mu \mathrm{L}$ of chloroform isoamyl alcohol (24:1) was added to each sample and vigorously mixed for $15 \mathrm{~s}$, and incubated at room temperature for $3 \mathrm{~min}$. Subsequently, centrifuged at 12,000 rpm for $15 \mathrm{~min}$ at $4{ }^{\circ} \mathrm{C}$, and the supernatant was recovered and $500 \mu \mathrm{L}$ of isopropanol was added (additionally, $150 \mu \mathrm{L}$ of sodium citrate $(0.8 \mathrm{M})$ and $150 \mu \mathrm{L}$ of sodium chloride $(1.2 \mathrm{M})$ were added to the tomato samples), and incubated at room temperature for $10 \mathrm{~min}$. Subsequently, the sample was centrifuged at 12,000 rpm for $10 \mathrm{~min}$ at $4{ }^{\circ} \mathrm{C}$, the supernatant was discarded, and the pellet washed with $1 \mathrm{~mL}$ of cold $75 \%$ ethanol, vortexed for 10 seconds, and centrifuged at $7500 \mathrm{rpm}$ for $5 \mathrm{~min}$ at $4{ }^{\circ} \mathrm{C}$, and the supernatant was discarded. Finally, the pellet with RNA was air dried and resuspended in sterile MQ water. For the tomato RNA samples an extra purification step was required so $50 \mu \mathrm{L}$ of $\mathrm{LiCl}$ $(8 \mathrm{M})$ was added and gently mixed; the samples were then incubated overnight at $4{ }^{\circ} \mathrm{C}$. The next day, the samples were centrifuged at $10,000 \mathrm{rpm}$ for $15 \mathrm{~min}$ at $4{ }^{\circ} \mathrm{C}$, the supernatant was discarded, and the pellet was resuspended in $100 \mu \mathrm{L}$ of water. Then, the RNA was precipitated by adding $10 \mu \mathrm{L}$ of sodium acetate $(3 \mathrm{M}) \mathrm{pH} 5.2$ and $250 \mu \mathrm{L}$ of cold $100 \%$ ethanol. The samples were mixed by inversion and placed at $-20^{\circ} \mathrm{C}$ for $2 \mathrm{~h}$. Subsequently, the samples were centrifuged at $12,000 \mathrm{rpm}$ for $15 \mathrm{~min}$ at $4{ }^{\circ} \mathrm{C}$, and the supernatant was discarded. The pellet was washed with $1 \mathrm{~mL}$ of $70 \%$ ethanol and centrifuged at $7500 \mathrm{rpm}$ for $5 \mathrm{~min}$ at $4{ }^{\circ} \mathrm{C}$. Finally, the pellet was dried and resuspended in $20 \mu \mathrm{L}$ of MQ water. The concentration and purity of RNA were analyzed in a NanoDrop spectrophotometer (NanoDrop Technologies, Wilmington, DE, USA), and the samples were analyzed by gel electrophoresis ( $1 \%$ agarose gel in $0.5 \times$ TBE buffer and stained with $0.001 \%$ ethidium bromide). For RT-PCR, RNA from Arabidopsis leaves and flowers of one or two days post-anthesis from tomato was used. The cDNA was obtained using the M-MLV reverse transcriptase enzyme (Invitrogen) according to the manual. $1 \mu \mathrm{L}$ of cDNA was used for RT-PCR analysis. The PCR conditions were $94^{\circ} \mathrm{C}$ for $3 \mathrm{~min} ; 35$ cycles of 94 ${ }^{\circ} \mathrm{C}$ for $30 \mathrm{~s}$, an annealing temperature of $53.7^{\circ} \mathrm{C}$ for GOBLET, $53.6^{\circ} \mathrm{C}$ for $N A C 1,53.9^{\circ} \mathrm{C}$ for NAM2, and $64{ }^{\circ} \mathrm{C}$ for pre-miR164a for $30 \mathrm{~s}$; and $30 \mathrm{~s}$ of extension at $72{ }^{\circ} \mathrm{C}$, and finally $4 \mathrm{~min}$ at $72{ }^{\circ} \mathrm{C}$. For ACTIN, 30 cycles and an annealing temperature of $61^{\circ} \mathrm{C}$ was used. Oligonucleotides for each target gene are given in Table S1. Expression of pre-miR164a was analyzed using oligonucleotides miR164-Fw (5'-TGC GTG TGA GCT AGT CTT CC-3') and miR164-Rv (5'-CAA CGA AGA GCT AGT CAA GAA CAA-3').

\subsection{Phenotypic and Molecular Characterization}

The phenotypes of each plant of the different lines were observed during development and compared with wild type (WT) plants. For the phenotypic characterization of Arabidopsis, secondary stems, the number of branches in the main stem, and the fruit number were analyzed. For the molecular characterization of Arabidopsis, the expression level of CUC1 (one target gene of miR164 in Arabidopsis) and pre-miR164a was analyzed by RT-PCR. For phenotypic analyses of tomato plants, at least 15 plants of six 164-OE transgenic lines were analyzed versus WT plants. In tomato, the parameters evaluated were size and serrations of third fully developed leaf from the basal part, the time taken to generate the first fruit, the number of fruits, fruit size, seed number, number of locules per fruit, and the number of days taken to change at one stage of development to another. The plant area of tomato was measured using the ImageJ program (National Institutes of Health, Bethesda, MD, USA). The expression level of GOBLET, NAC1, NAM2, and NAM3 (target genes of miR164 in tomato), and pre-miR164a was analyzed in tomato flowers by RT-PCR. 


\subsection{Statistical Analysis}

The data obtained from the phenotypic analyses of both Arabidopsis and tomato were analyzed using the Stat graphics program (Statpoint Technologies, Inc., The Plains, VA, USA), in which variance analysis (ANOVA) is applied to each data set of the parameters valued, followed by a multiple range test when the ANOVA detects significant differences $(a l p h a=0.05)$ between averages. The test used was Least Significant Difference (LSD) - the least significant difference at a confidence level of 95\%. In addition, graphs of averages were generated with intervals based on the LSD test at $95 \%$, which are built by the program so that if two means are equal the intervals overlap $95 \%$ of times. In cases where the test detected a statistically significant difference $(p<0.05)$ of the different lines evaluated versus WT plants, an asterisk $\left({ }^{*}\right)$ was placed.

\section{Conclusions}

The results obtained in this study demonstrate that the constitutive miR164 expression affects the morphology of Arabidopsis and tomato, and it affects the transition from the vegetative to the reproductive phase in Arabidopsis. Moreover, the miR164 overexpression affects the time required for each developmental stage of tomato fruit. At the moment, we cannot conclude which target genes of miR164 cause the phenotypes.

The abundance of a miRNA in a plant is probably critical in the determination of the desirable characteristic(s) in each species. Therefore, it is necessary to carry out detailed studies to determine the ideal expression level of each miRNA. Moreover, it is necessary to perform a precise characterization of each line, in order to know the effect of the concentration between the miRNA and its target genes. In this case, follow-up studies should be performed to analyze the abundance of the mature miR164 and the correlation with its target genes in the 164-OE lines, as well as the analyses of all target genes of miR164, to give a better interpretation of the obtained results with the purpose of improving fruit development and quality. Based on our results using miR164, and based on other studies, controlling the abundance of a miRNA is a good strategy for developing biotechnological applications for the improvement of agronomically interesting traits.

Supplementary Materials: The following are available online at www.mdpi.com/2073-4395/7/3/48/s1, Figure S1: Expression analyses of pre-miR164a in Arabidopsis and tomato 164-OE lines, Figure S2: Plant area of different 164-OE tomato lines, Table S1: Oligonucleotides used to amplify a fragment of different miR164 target genes.

Acknowledgments: We thank Lázaro E. P. Peres for the tomato MT $R g-1$ seeds and the Laboratorio de Transformación de la Unidad Irapuato del CINVESTAV for the generation of transgenic tomato plants. We also acknowledge the comments and suggestions from two anonymous reviewers. We thank the Mexican National Council of Science and Technology (CONACyT) for a fellowship to YRS (371202). This work in the de Folter laboratory was financed by the CONACyT grant CB-2012-177739 and FC-2015-2/1061, and SdF acknowledges support of the European Union H2020-MSCA-RISE-2015 project ExpoSEED (grant No. 691109).

Author Contributions: F.d.F.R.C., Y.R.S., N.M.M., and S.D.F. conceived and designed the experiments; F.d.F.R.C., Y.R.S., R.M.C.R., V.L.G., and K.L.G.A. performed the experiments; F.d.F.R.C., Y.R.S. and S.d.F. analyzed the data; S.d.F. contributed reagents/materials/analysis tools; F.d.F.R.C. and S.d.F. wrote the paper.

Conflicts of Interest: The authors declare no conflict of interest.

\section{References}

1. Zhang, B.; Pan, X.; Cannon, C.H.; Cobb, G.P.; Anderson, T.A. Conservation and divergence of plant microRNA genes. Plant J. 2006, 46, 243-259. [CrossRef] [PubMed]

2. Taylor, R.S.; Tarver, J.E.; Hiscock, S.J.; Donoghue, P.C.J. Evolutionary history of plant microRNAs. Trends Plant Sci. 2014, 19, 175-182. [CrossRef] [PubMed]

3. Axtell, M.J.; Bowman, J.L. Evolution of plant microRNAs and their targets. Trends Plant Sci. 2008, 13, 343-349. [CrossRef] [PubMed]

4. Cuperus, J.T.; Fahlgren, N.; Carrington, J.C. Evolution and functional diversification of miRNA genes. Plant Cell 2011, 23, 431-442. [CrossRef] [PubMed] 
5. Chávez Montes, R.A.; Rosas-Cárdenas, F.D.F.; De Paoli, E.; Accerbi, M.; Rymarquis, L.A.; Mahalingam, G.; Marsch-Martínez, N.; Meyers, B.C.; Green, P.J.; de Folter, S. Sample sequencing of vascular plants demonstrates widespread conservation and divergence of microRNAs. Nat. Commun. 2014, 5, 3722. [PubMed]

6. Jones-Rhoades, M.W. Conservation and divergence in plant microRNAs. Plant Mol. Biol. 2011, 80, 3-16. [CrossRef] [PubMed]

7. Li, A.; Mao, L. Evolution of plant microRNA gene families. Cell Res. 2007, 17, 212-218. [CrossRef] [PubMed]

8. Fahlgren, N.; Jogdeo, S.; Kasschau, K.D.; Sullivan, C.M.; Chapman, E.J.; Laubinger, S.; Smith, L.M.; Dasenko, M.; Givan, S.A.; Weigel, D.; et al. MicroRNA gene evolution in Arabidopsis lyrata and Arabidopsis thaliana. Plant Cell 2010, 22, 1074-1089. [CrossRef] [PubMed]

9. Nozawa, M.; Miura, S.; Nei, M. Origins and evolution of microRNA genes in plant species. Genome Biol. Evol. 2012, 4, 230-239. [CrossRef] [PubMed]

10. Voinnet, O. Origin, biogenesis, and activity of plant microRNAs. Cell 2009, 136, 669-687. [CrossRef] [PubMed]

11. Mallory, A.C.; Bouché, N. MicroRNA-directed regulation: To cleave or not to cleave. Trends Plant Sci. 2008, 13, 359-367. [CrossRef] [PubMed]

12. Cech, T.R.; Steitz, J.A. Review the noncoding RNA revolution-Trashing old rules to forge new ones. Cell 2014, 157, 77-94. [CrossRef] [PubMed]

13. Kim, J.H.; Woo, H.R.; Kim, J.; Lim, P.O.; Lee, I.C.; Choi, S.H.; Hwang, D.; Nam, H.G. Trifurcate feed-forward regulation of age-dependent cell death involving miR164 in Arabidopsis. Science 2009, 323, 1053-1057. [CrossRef] [PubMed]

14. Rosas-Cárdenas, F.D.F.; De Folter, S. Conservation, divergence and abundance of miRNAs and their effect in plants. In RNA Technologies, Plant Epigenetics; Rajewsky, N., Jurga, S., Barciszewski, J., Eds.; Springer: Berlin, Germany, 2017; pp. 1-22.

15. Jin, D.; Wang, Y.; Zhao, Y.; Chen, M. MicroRNAs and their cross-talks in plant development. J. Genet. Genom. 2013, 40, 161-170. [CrossRef] [PubMed]

16. Cao, D.; Li, Y.; Wang, J.; Nan, H.; Wang, Y.; Lu, S.; Jiang, Q.; Li, X.; Shi, D.; Fang, C.; et al. GmmiR156b overexpression delays flowering time in soybean. Plant Mol. Biol. 2015, 89, 353-363. [CrossRef] [PubMed]

17. Lee, Y.-S.; Lee, D.-Y.; Cho, L.-H.; An, G. Rice miR172 induces flowering by suppressing OsIDS1 and SNB, two AP2 genes that negatively regulate expression of Ehd1 and florigens. Rice 2014, 7, 31. [CrossRef] [PubMed]

18. Yao, J.-L.; Tomes, S.; Xu, J.; Gleave, A.P. How microRNA172 affects fruit growth in different species is dependent on fruit type. Plant Signal. Behav. 2016, 2324, e1156833. [CrossRef] [PubMed]

19. Silva, G.F.F.E.; Silva, E.M.; Da Silva Azevedo, M.; Guivin, M.A.C.; Ramiro, D.A.; Figueiredo, C.R.; Carrer, H.; Peres, L.E.P.; Nogueira, F.T.S. MicroRNA156-targeted SPL/SBP box transcription factors regulate tomato ovary and fruit development. Plant J. 2014, 78, 604-618. [CrossRef] [PubMed]

20. Xu, M.; Hu, T.; Smith, M.R.; Poethig, R.S. Epigenetic regulation of vegetative phase change in Arabidopsis. Plant Cell 2016, 28, 28-41. [CrossRef] [PubMed]

21. Fu, C.; Sunkar, R.; Zhou, C.; Shen, H.; Zhang, J.-Y.; Matts, J.; Wolf, J.; Mann, D.G.J.; Stewart, C.N.; Tang, Y.; et al. Overexpression of miR156 in switchgrass (Panicum virgatum L.) results in various morphological alterations and leads to improved biomass production. Plant Biotechnol. J. 2012, 10, 443-452. [CrossRef] [PubMed]

22. Jones-Rhoades, M.W.; Bartel, D.P. Computational identification of plant microRNAs and their targets, including a stress-induced miRNA. Mol. Cell 2004, 14, 787-799. [CrossRef] [PubMed]

23. Reinhart, B.J.; Weinstein, E.G.; Rhoades, M.W.; Bartel, B.; Bartel, D.P. MicroRNAs in plants. Genes Dev. 2002, 16, 1616-1626. [CrossRef] [PubMed]

24. Hendelman, A.; Stav, R.; Zemach, H.; Arazi, T. The tomato NAC transcription factor SINAM2 is involved in flower-boundary morphogenesis. J. Exp. Bot. 2013, 64, 5497-5507. [CrossRef] [PubMed]

25. Mallory, A.C.; Dugas, D.V.; Bartel, D.P.; Bartel, B. MicroRNA regulation of NAC-domain targets is required for proper formation and separation of adjacent embryonic, vegetative, and floral organs. Curr. Biol. 2004, 14, 1035-1046. [CrossRef] [PubMed]

26. Baker, C.C.; Sieber, P.; Wellmer, F.; Meyerowitz, E.M. The early extra petals1 mutant uncovers a role for microRNA miR164c in regulating petal number in Arabidopsis. Curr. Biol. 2005, 15, 303-315. [CrossRef] [PubMed] 
27. Guo, H.; Xie, Q.; Fei, J.; Chua, N. MicroRNA directs mRNA cleavage of the transcription factor NAC1 to downregulate auxin signals for Arabidopsis lateral root development. Plant Cell 2005, 17, 1376-1386. [CrossRef] [PubMed]

28. Laufs, P.; Peaucelle, A.; Morin, H.; Traas, J. MicroRNA regulation of the CUC genes is required for boundary size control in Arabidopsis meristems. Development 2004, 131, 4311-4322. [CrossRef] [PubMed]

29. Nikovics, K.; Blein, T.; Peaucelle, A.; Ishida, T.; Morin, H.; Aida, M.; Laufs, P. The balance between the MIR164A and CUC2 genes controls leaf margin serration in Arabidopsis. Plant Cell 2006, 18, 2929-2945. [CrossRef] [PubMed]

30. Sieber, P.; Wellmer, F.; Gheyselinck, J.; Riechmann, J.L.; Meyerowitz, E.M. Redundancy and specialization among plant microRNAs: Role of the MIR164 family in developmental robustness. Development 2007, 134, 1051-1060. [CrossRef] [PubMed]

31. Blein, T.; Pulido, A.; Vialette-Guiraud, A.; Nikovics, K.; Morin, H.; Hay, A.; Johansen, I.E.; Tsiantis, M.; Laufs, P. A conserved molecular framework for compound leaf development. Science 2008, 322, 1835-1839. [CrossRef] [PubMed]

32. Koyama, T.; Mitsuda, N.; Seki, M.; Shinozaki, K.; Ohme-Takagi, M. TCP transcription factors regulate the activities of ASYMMETRIC LEAVES1 and miR164, as well as the auxin response, during differentiation of leaves in Arabidopsis. Plant Cell 2010, 22, 3574-3588. [CrossRef] [PubMed]

33. Hasson, A.; Plessis, A.; Blein, T.; Adroher, B.; Grigg, S.; Tsiantis, M.; Boudaoud, A.; Damerval, C.; Laufs, P. Evolution and diverse roles of the CUP-SHAPED COTYLEDON genes in Arabidopsis leaf development. Plant Cell 2011, 23, 54-68. [CrossRef] [PubMed]

34. Berger, Y.; Harpaz-Saad, S.; Brand, A.; Melnik, H.; Sirding, N.; Alvarez, J.P.; Zinder, M.; Samach, A.; Eshed, Y.; Ori, N. The NAC-domain transcription factor GOBLET specifies leaflet boundaries in compound tomato leaves. Development 2009, 136, 823-832. [CrossRef] [PubMed]

35. Mallory, A.C.; Vaucheret, H. MicroRNAs: Something important between the genes. Curr. Opin. Plant Biol. 2004, 7, 120-125. [CrossRef] [PubMed]

36. Raman, S.; Greb, T.; Peaucelle, A.; Blein, T.; Laufs, P.; Theres, K. Interplay of miR164, CUP-SHAPED COTYLEDON genes and LATERAL SUPPRESSOR controls axillary meristem formation in Arabidopsis thaliana. Plant J. 2008, 55, 65-76. [CrossRef] [PubMed]

37. Vialette-Guiraud, A.C.M.; Chauvet, A.; Gutierrez-Mazariegos, J.; Eschstruth, A.; Ratet, P.; Scutt, C.P. A conserved role for the NAM/miR164 developmental module reveals a common mechanism underlying carpel margin fusion in monocarpous and syncarpous eurosids. Front. Plant Sci. 2016, 6, 1239. [CrossRef] [PubMed]

38. Rhoades, M.W.; Reinhart, B.J.; Lim, L.P.; Burge, C.B.; Bartel, B.; Bartel, D.P. Prediction of plant microRNA targets. Cell 2002, 110, 513-520. [CrossRef]

39. Schwab, R.; Palatnik, J.F.; Riester, M.; Schommer, C.; Schmid, M.; Weigel, D. Specific effects of microRNAs on the plant transcriptome. Dev. Cell 2005, 8, 517-527. [CrossRef] [PubMed]

40. Karlova, R.; van Haarst, J.C.; Maliepaard, C.; van de Geest, H.; Bovy, A.G.; Lammers, M.; Angenent, G.C.; de Maagd, R.A. Identification of microRNA targets in tomato fruit development using high-throughput sequencing and degradome analysis. J. Exp. Bot. 2013, 64, 1863-1878. [CrossRef] [PubMed]

41. Kim, H.J.; Hong, S.H.; Kim, Y.W.; Lee, I.H.; Jun, J.H.; Phee, B.K.; Rupak, T.; Jeong, H.; Lee, Y.; Hong, B.S.; et al. Gene regulatory cascade of senescence-associated NAC transcription factors activated by ETHYLENE-INSENSITIVE2-mediated leaf senescence signalling in Arabidopsis. J. Exp. Bot. 2014, 65, 4023-4036. [CrossRef] [PubMed]

42. Liu, Y.; Wang, L.; Chen, D.; Wu, X.; Huang, D.; Chen, L.; Li, L.; Deng, X. Genome-wide comparison of microRNAs and their targeted transcripts among leaf, flower and fruit of sweet orange. BMC Genom. 2014, 15, 695. [CrossRef] [PubMed]

43. Pantaleo, V.; Szittya, G.; Moxon, S.; Miozzi, L.; Moulton, V.; Dalmay, T.; Burgyan, J. Identification of grapevine microRNAs and their targets using high-throughput sequencing and degradome analysis. Plant J. 2010, 62, 960-976. [PubMed]

44. Sun, X.; Korir, N.K.; Han, J.; Shangguan, L.F.; Kayesh, E.; Leng, X.P.; Fang, J.G. Characterization of grapevine microR164 and its target genes. Mol. Biol. Rep. 2012, 39, 9463-9472. [CrossRef] [PubMed] 
45. Lopez-Gomollon, S.; Mohorianu, I.; Szittya, G.; Moulton, V.; Dalmay, T. Diverse correlation patterns between microRNAs and their targets during tomato fruit development indicates different modes of microRNA actions. Planta 2012, 236, 1875-1887. [CrossRef] [PubMed]

46. Rosas-Cárdenas, F.D.F.; Caballero-Pérez, J.; Ramos, X.G.; Cruz-Hernández, A.; Marsch-Martínez, N.; de Folter, S. miRNA expression during prickly pear cactus fruit development. Planta 2014, 241, 435-448. [CrossRef] [PubMed]

47. Bilsborough, G.D.; Runions, A.; Barkoulas, M.; Jenkins, H.W.; Hasson, A.; Galinha, C.; Laufs, P.; Hay, A.; Prusinkiewicz, P.; Tsiantis, M. Model for the regulation of Arabidopsis thaliana leaf margin development. Proc. Natl. Acad. Sci. USA 2011, 108, 3424-3429. [CrossRef] [PubMed]

48. Adam, H.; Marguerettaz, M.; Qadri, R.; Adroher, B.; Richaud, F.; Collin, M.; Thuillet, A.-C.; Vigouroux, Y.; Laufs, P.; Tregear, J.W.; et al. Divergent expression patterns of miR164 and CUP-SHAPED COTYLEDON genes in palms and other monocots: Implication for the evolution of meristem function in angiosperms. Mol. Biol. Evol. 2011, 28, 1439-1454. [CrossRef] [PubMed]

49. Lauter, N.; Kampani, A.; Carlson, S.; Goebel, M.; Moose, S.P. microRNA172 down-regulates glossy15 to promote vegetative phase change in maize. Proc. Natl. Acad. Sci. USA 2005, 102, 9412-9417. [CrossRef] [PubMed]

50. Wang, J.W.; Park, M.Y.; Wang, L.J.; Koo, Y.; Chen, X.Y.; Weigel, D.; Poethig, R.S. MiRNA control of vegetative phase change in trees. PLoS Genet. 2011, 7, 21-25. [CrossRef] [PubMed]

51. Galbiati, F.; Sinha Roy, D.; Simonini, S.; Cucinotta, M.; Ceccato, L.; Cuesta, C.; Simaskova, M.; Benkova, E.; Kamiuchi, Y.; Aida, M.; et al. An integrative model of the control of ovule primordia formation. Plant J. 2013, 76, 446-455. [CrossRef] [PubMed]

52. Gonçalves, B.; Hasson, A.; Belcram, K.; Cortizo, M.; Morin, H.; Nikovics, K.; Vialette-Guiraud, A.; Takeda, S.; Aida, M.; Laufs, P.; et al. A conserved role for CUP-SHAPED COTYLEDON genes during ovule development. Plant J. 2015, 83, 732-742. [CrossRef] [PubMed]

53. Pino, L.E.; Lombardi-Crestana, S.; Azavedo, M.A.; Scotton, D.C.; Borgo, L.; Quecini, V.; Figueira, A.; Peres, L.E. The Rg1 allele as a valuable tool for genetic transformation of the tomato "Micro-Tom" model system. Plant Methods 2010, 6, 23. [CrossRef] [PubMed]

54. Clough, S.J.; Bent, A.F. Floral dip: A simplified method for Agrobacterium-mediated transformation of Arabidopsis thaliana. Plant J. 1998, 16, 735-743. [CrossRef] [PubMed] 